\title{
Social Resources and Longevity: Findings from the Georgia Centenarian Study
}

\author{
G. Kevin Randall ${ }^{a}$ Peter Martin ${ }^{b}$ Maurice McDonald ${ }^{b}$ Leonard W. Poon ${ }^{c}$ \\ for the Georgia Centenarian Study \\ ${ }^{a}$ Family and Consumer Sciences, Bradley University, Peoria, Ill., ${ }^{\text {b }}$ lowa State University, Ames, lowa, and \\ 'University of Georgia, Athens, Ga., USA
}

\section{Key Words}

Oldest old · Centenarian · Social resources · Social

provisions $\cdot$ Nursing home

\begin{abstract}
Background: As the proportion of adults aged 85 and older increases, investigations of resources essential for adapting to the challenges of aging are required. Objective: To comprehensively investigate the social resources of cognitively intact centenarians participating in the Georgia Centenarian Study and the association between these resources and residence status. Methods: Two widely used measures of social resources were investigated among participants living in private homes, personal care facilities, and nursing homes. Logistic regression was used to determine significant predictors of nursing home residence. Results: Differences in levels of social resources were found between centenarians and octogenarians, and among centenarians in different living situations. Analyses revealed differential findings between self- and proxy reports. Controlling for education, activities of daily living, and financial ability to meet needs, only one of the two social resources measures significantly reduced the odds of nursing home residence. Conclusion: The findings of this study add to the existing literature on one of the basic adaptive resources (social resources) for centenarians.
\end{abstract}

Whether a more specific assessment of network contact is employed, or a more global assessment is used, differences in these constructs exist between centenarians and octogenarians, among centenarians in differing living conditions, and across types of informants. Researchers examining the different resources that may contribute to extraordinary longevity and positive adaptation may find it essential to differentiate between the oldest old and centenarians, and to account for differences based upon measure, reporter type, and centenarian residence status.

Copyright $\odot 2010$ S. Karger AG, Basel

The limit of human life expectancy has yet to be reached, leading many to investigate factors essential to positive aging among the oldest old (85 years and older), especially as the proportion of this group in the US increased $225.2 \%$ between 1900 and $1996[1,2]$. Where and with whom older adults live and associate, and various assessments of the types of resources utilized for adapta-

Additional authors include S.M. Jazwinski, R.C. Green, M. Gearing, W.R. Markesbery, J.L. Woodard, M.A. Johnson, J.S. Tenover, I.C. Siegler, W.L. Rodgers, D.B. Hausman, C. Rott, A. Davey, and J. Arnold.

\section{KARGER}

Fax +4161306 1234

E-Mail karger@karger.ch

www.karger.com
(C) 2010 S. Karger AG, Basel

0304-324X/10/0561-0106\$26.00/0

Accessible online at:

www.karger.com/ger
G. Kevin Randall, MD

Family and Consumer Sciences, 05 Bradley Hall, Bradley University 1501 West Bradley Avenue

Peoria, IL 61625 (USA)

Tel. +1 309677 3202, Fax +1 309677 3813, E-Mail krandall@bradley.edu 
tion to the changes associated with aging are critical components of these studies [3-5]. To date, few studies have focused on the social resources of centenarians [6], and none were found focusing on social resources and residence status of centenarians. When assessing older adults, it is often necessary, due to hearing loss or other physical difficulties associated with aging, to include proxy reports in addition to self-reports [7]. A direct comparison of proxy and self-reports of social resources measures for centenarians has not been reported. The present study focused on these gaps in the current knowledge base.

Distinctions between structure (network size/frequency of contact) and function (type of support provided) of social relationships are common $[8,9]$. Two popularly used measures include Social Resources [10] (SR; from the Duke OARS) and Social Provisions (SP) from the Social Provisions Scale [11]. SR taps the extent and perceived adequacy of social contacts with friends and family. SP includes a number of components aimed at tapping the various functions of social support. The present study examined both assessments, providing an opportunity to compare two commonly used measures of structure and function among centenarians. Baltes' [12] well-known principles for individual development over one's lifespan, especially the increasing need for cultural or societal resources of older adults, and the emphasis on proximal influences of development explicated by Martin and Martin [13] motivated the present study's examination of centenarians' social resources with respect to their living situation.

Past studies have focused on social resources and institutionalization in nursing homes $[14,15]$. Since nursing home placement is very common for the oldest population, and the cost of such care was estimated to be about 150 billion dollars for the year 2007 in the US, the present study investigated the relationship between social resources and the residence status of centenarians, controlling for a number of known risk factors. We addressed whether or not social resources are associated with nursing home residence after accounting for the contributions of age, cognitive deficiencies, functional impairment, and economic resources. Thus, based on the principles proffered by Baltes [12] and the extant empirical literature $[6,13,16]$, we predicted centenarians would exhibit the lowest levels of social resources relative to octogenarians and, in particular, centenarians residing in nursing homes would exhibit the lowest levels relative to those residing in private homes or personal care facilities. Similarly, we predicted that higher levels of social resources would reduce the probability of nursing home residence. Finally, as a research question, we investigated how different reporter assessments (e.g. self- vs. proxy report) influenced the outcomes of our investigation.

\section{Method}

Participants and Procedure

Data for this study came from a population-based sample of centenarians and octogenarians collected between 2002 and 2005 from the state of Georgia. The Georgia Centenarian Study [17] investigated factors related to survival and functioning of centenarians. Participants scored 17 or higher (mean: 24.74, SD: 3.92) on the Mini-Mental Status Examination (MMSE) [18]. No screening for neurological or psychiatric illness was performed. Thus, 158 cognitively intact, community-dwelling, and institutionalized near-centenarians and centenarians (98 years and older; average age: 99.82, range: $98-109$ ) and 76 octogenarians (average age: 84.25 , range: $81-90$ ) were included in this study. Of the centenarian participants, $78.5 \%$ were female, $85 \%$ white, $15 \%$ black, and $85 \%$ widowed, whereas only $6 \%$ were married. Of the octogenarian participants, $64.5 \%$ were female, $84.2 \%$ white, $15.8 \%$ black, and $47.4 \%$ widowed, whereas $44.7 \%$ were married. Proxies provided additional reports for both age groups. Further details on the study's sampling, data collection, and design are provided by Poon et al. [17].

\section{Measures}

Social Resources. SR was measured using 3 questions from the Duke OARS [10] interaction dimension of social support. SR is an assessment of social support structure measuring the size of the support network and frequency of contact. One question assessed the number of individuals the participant knew well enough to visit with in their homes, the 2 nd question asked about the number of past week phone conversations, and the 3 rd question assessed the number of visits they had in the past week with someone they did not live with. Each question was scaled from 0-3, with higher scores reflecting more contact. Cronbach's $\alpha$ for octogenarians and centenarians on this index was 0.42 for proxy reports and 0.40 for self-reports. A recent study investigated SR and reported alphas for the interaction dimension ranging from 0.44 to 0.61 , noting that such results demonstrated a breadth of conceptual assessment by the items rather than a selection of items designed to maximize internal consistency [8]. It is our contention that such is the case with these three items that make up the interaction dimension of SR. In addition to being comprised of only three items, this dimension or factor appears to assess a breadth of structure and (at times) the items may not necessarily be related. For example, centenarians who receive many visitors are not necessarily the ones who talk much on the phone, perhaps due to hearing impairment, which is quite common in very late life. Secondly, these three items may in fact serve as a checklist of social resources structure and, as such, may not estimate a unidimensional construct. Expecting relatively high inter-item correlations and associated internal consistency for such a 3-item scale may be unwarranted. A full discussion regarding why checklist assessments often exhibit low internal consistency is found in Herbert and Cohen [19].

Social Provisions. SP was measured using an adapted 12-item shortened version of the Social Provisions Scale [11]. These items 
Table 1. Mean differences for social resources constructs (self-report) by age group and residence status

\begin{tabular}{|c|c|c|c|c|c|c|c|}
\hline & \multicolumn{2}{|c|}{$80 \mathrm{~s}$} & \multicolumn{2}{|c|}{80 s vs. 100 s } & \multirow{2}{*}{$\frac{100 \mathrm{~s}}{\text { mean }(\mathrm{SD})}$} & \multicolumn{2}{|c|}{100 s res. status } \\
\hline & $\mathrm{n}$ & mean (SD) & $\mathrm{t}$ & $\mathrm{n}$ & & $\mathrm{F}$ & $\eta^{2}$ \\
\hline OARS Social Resources & & & & & & $5.27^{* *}$ & 0.08 \\
\hline Private home & 68 & $7.57(0.95)$ & $2.03^{*}$ & 76 & $7.16^{\mathrm{a}}(1.43)$ & & \\
\hline Nursing home & 1 & 9.00 & & 28 & $6.11^{\mathrm{b}}(2.06)$ & & \\
\hline Personal care & 1 & 7.00 & & 28 & $7.21^{\mathrm{a}}(1.20)$ & & \\
\hline Social Provisions Scale & & & & & & 0.982 & 0.02 \\
\hline Private home & 67 & $37.45(3.20)$ & $4.66^{* * *}$ & 68 & $35.24(2.21)$ & & \\
\hline Nursing home & 1 & 34.00 & & 18 & $34.39(2.73)$ & & \\
\hline Personal care & 0 & & & 23 & $35.30(2.65)$ & & \\
\hline
\end{tabular}

Means in the same column that do not share superscripts differ at $\mathrm{p}<0.05$ in the Scheffé post hoc test. ${ }^{*} \mathrm{p}<0.05,{ }^{* *} \mathrm{p}<0.01,{ }^{* * *} \mathrm{p}<0.001$.

were scaled so that higher scores indicated higher levels of social provisions and summed to create a variable that could range from 12 to 48 . Cronbach's $\alpha$ for this scale was 0.75 for self-reports and 0.69 for proxy-reports.

Activities of Daily Living. Two commonly used dimensions, instrumental activities of daily living (ADLs; 7 items) and physical ADLs (6 items) comprise the self-care capacity assessment [10]. Cronbach's $\alpha$ for this measure was 0.88 for self-reports and 0.92 for proxy reports. ADLs were scaled so that higher scores indicate higher levels of self-care capacity.

Finances. A single question from Fillenbaum [10], 'How well does the amount of money you have take care of your needs?', was used to assess the participant's financial situation. This was scaled so that $0=$ poorly, $1=$ fairly well, and $2=$ very well.

Education. Years of education was assessed with a Likert-type scale ranging from 1 to $8(1=0-4$ years; $8=$ post-graduate college).

Age Group and Residence Status. Both of these were coded categorically in order to differentiate between participants in their 80 s and 100 s, and among the three residence locations (i.e. private home, nursing home, and personal care).

\section{Data Analysis}

Summary scores were created for the interaction dimension of SR and SP by reporter for participants in their 80 s and 100s. Independent $t$ tests were used to compare the differences in SR and SP between those in their 80 s and 100 s who reside in a private home for both reporter types. ANOVA assessed mean differences in SR and SP for those in their 100s among the three residence locations. Based on the differential results from these analyses, we then conducted dependent paired t tests for each measure between reporter types by residence status. We then specified a logistic regression model predicting residence status. Because a trend of significant differences was not found between residents in private homes or personal care facilities on the measures of social resources, the dichotomous outcome in our logistic analysis was residence in a nursing home or not (i.e. residence in a private home or personal care facility).

\section{Results}

Centenarians self-reported significantly lower levels of social resources than octogenarians for both measures (SR: $\mathrm{t}=2.03, \mathrm{p}<0.05 ; \mathrm{SP}: \mathrm{t}=4.66, \mathrm{p}<0.001$; table 1 ). This significant difference was not found for the proxy reports of either measure (table 2). Centenarians living in nursing homes self-reported significantly lower SR than centenarians living in either private homes or personal care facilities $[\mathrm{F}(2,131)=5.27, \mathrm{p}<0.01$; table 1$]$. Post hoc Scheffé analyses indicated that self-reported SR for centenarians living in nursing homes was significantly lower than those living in either private homes $(\mathrm{p}=0.01)$ or personal care facilities $(p=0.03)$. No significant difference was found among location or place for centenarians when SP was assessed by self-report (table 1). Proxy-report assessments of SP and SR were compared between centenarians and octogenarians living in private homes (table 2). In direct contrast to the self-report findings, no significant differences between centenarians and octogenarians in SP or SR were found in the proxy reports. However, when proxy reports of centenarians were compared by residence status, participants in nursing homes tended to have the lowest levels of both SR and SP. The results for SR were significant $[\mathrm{F}(2,124)=3.20, \mathrm{p}<0.05]$. Post hoc Scheffé analyses indicated that levels of SR for nursing home residents tended to differ from those in private homes $(\mathrm{p}=0.07)$ and personal care facilities $(\mathrm{p}=$ 0.09 ). Also, a significant difference in levels of proxy-reported SP was found across residence status $[\mathrm{F}(2,120)=$ $3.91, \mathrm{p}<0.05]$. Post hoc Scheffé analyses indicated that levels of SP for nursing home residents differed significantly from those in personal care facilities $(p=0.03)$, but 
Table 2. Mean differences for social resources constructs (proxy report) by age group and residence status

\begin{tabular}{|c|c|c|c|c|c|c|c|}
\hline & \multicolumn{2}{|c|}{$80 \mathrm{~s}$} & \multicolumn{2}{|c|}{80 s vs. 100 s } & \multirow{2}{*}{$\frac{100 \mathrm{~s}}{\text { mean }(\mathrm{SD})}$} & \multicolumn{2}{|c|}{100 s res. status } \\
\hline & $\mathrm{n}$ & mean (SD) & $\mathrm{t}$ & $\mathrm{n}$ & & $\mathrm{F}$ & $\eta^{2}$ \\
\hline OARS Social Resources & & & & & & $3.20^{*}$ & 0.05 \\
\hline Private home & 62 & $6.97(1.61)$ & 0.66 & 69 & $7.13^{\mathrm{a}}(1.49)$ & & \\
\hline Nursing home & 2 & $5.00(4.24)$ & & 27 & $6.33^{\mathrm{b}}(1.62)$ & & \\
\hline Personal care & 1 & 6.00 & & 29 & $7.24^{\mathrm{a}}(1.50)$ & & \\
\hline Social Provisions Scale & & & & & & $3.91^{*}$ & 0.06 \\
\hline Private home & 55 & $39.13(4.80)$ & 0.57 & 65 & $38.66^{\mathrm{a}, \mathrm{b}}(4.20)$ & & \\
\hline Nursing home & 2 & $33.50(3.54)$ & & 28 & $36.61^{\mathrm{a}}(5.02)$ & & \\
\hline Personal care & 1 & 32.00 & & 28 & $39.75^{\mathrm{b}}(3.78)$ & & \\
\hline
\end{tabular}

Means in the same column that do not share superscripts differ at $\mathrm{p}<0.10$ in the Scheffé post hoc test for OARS social resources; $\mathrm{p}<0.05$ for Social Provisions Scale. ${ }^{*} \mathrm{p}<0.05$.

not those residing in a private home $(\mathrm{p}=0.11)$. We conducted dependent paired $t$ tests between the self- and proxy reports of SR and SP by residence status, and no significant differences between the self- and proxy reports were found for SR. Self-reporting of SP by centenarians was significantly lower than proxy reporting for those residing in private homes $(t=6.74, \mathrm{p}<0.001)$, nursing homes $(\mathrm{t}=2.95, \mathrm{p}<0.05)$, and personal care facilities $(\mathrm{t}=5.50, \mathrm{p}<0.001)$.

Because nursing home residents tended to report lower levels of SR and SP relative to the other two categories (and these two tended not to be different), we created a dichotomous outcome measure assessing residence in a nursing home (1) or not (0). We controlled for years of education, levels of ADLs, the ability to meet financial needs, and included both SR and SP as predictors. Analyses for both self- and proxy report measures were conducted. No significant results were obtained for proxy report measures of SR and SP. However, we did find significant predictors for the self-report measures (table 3). The model fit the data well $(94.2 \%$ overall correct classification; Cox and Snell $\mathrm{R}^{2}=0.232$; Nagelkerke $\mathrm{R}^{2}=0.538$ ). In this model, SR was a significant predictor $(p=0.004)$, reducing the probability of nursing home placement, whereas SP was not significant $(\mathrm{p}=0.08)$.

\section{Discussion}

Our findings were consistent with the principles of individual development across the lifespan [12, 13] that guided our hypotheses. Centenarians living in private homes experienced lower levels of self-reported social re-
Table 3. Logistic regression results for nursing home (self-report)

\begin{tabular}{lllll}
\hline Variable & $\mathrm{b}$ & $\mathrm{SE}$ & $\mathrm{p}$ & $\operatorname{Exp}(\mathrm{B})$ \\
\hline Education & -0.171 & 0.293 & 0.560 & 0.843 \\
ADL & -0.295 & 0.131 & 0.025 & 0.745 \\
Finances & -0.636 & 1.169 & 0.586 & 0.529 \\
Social provisions & 0.439 & 0.252 & 0.082 & 1.551 \\
Social resources & -1.378 & 0.474 & 0.004 & 0.252 \\
Constant & -0.994 & 6.825 & 0.884 & 0.370 \\
\hline
\end{tabular}

Cox and Snell $\mathrm{R}^{2}=0.232$; Nagelkerke $\mathrm{R}^{2}=0.538$.

sources on both measures (OARS SR, and SP) compared to those in their 80 s. Thus, age-related decline likely occurs as the centenarian often outlives a spouse, close friends, and some children. This finding did not hold for the proxy report of SR or SP; no significant differences between those in their 80s and 100s were found. Differential assessments, based upon type of informant, were found. When rating the oldest old, it appears that proxies do not differentiate between the two groups on either measure. It is interesting to note that the amount of variance tended to increase with proxy reports. However, when we directly compared the self- and proxy reports of centenarians' SR and SP by residence status, a clear trend emerged: no differences were found according to reporter for SR, whereas for each residence status, proxy reports of SP were significantly higher than self-reports. This could be an artifact of measurement confounds such as nonequivalence of the constructs between the age groups. 
Others have attempted to explain similar findings with different measures. For example, one study compared three measures of physical functioning in a community-dwelling sample of older adults [20] and concluded that the instruments might measure different constructs. However, we believe that this finding highlights the difference between a structural measure of social resources such as SR (e.g. an assessment of network size and/or frequency of contact) and a functional measure of social resources such as SP (e.g. the type of support provided). In addition, SP is a rather global and subjective functional measure (6 dimensions are assessed), whereas SR tends to tap a quantifiable or more objective amount of social assistance. This might explain why proxies consistently reported significantly larger levels of SP than self-reports of centenarians and why proxy reports vary more than self-reports.

The association between nursing home residence and self-reported SR adds to the above argument about the sensitivity of SR as an assessment of structure. Over and above the contribution of SP, SR significantly reduced the likelihood of residence in a nursing home by a centenarian, which is consistent with two major reviews of the literature regarding predictors of nursing home placement $[14,15]$. However, our study may be the first to report this for centenarians. Thus, the differentiation between a structural and functional measure of social resources when assessing centenarians is, we believe, a key contribution of this study. Practitioners and those who regularly work with community-dwelling individuals advancing toward centenarian status may want to pay particular care not only to the functional health of centenarians, but in the case of SR, the amount of contact the centenarian has had with someone in their network over the past week.

Whether a more specific assessment of network contact such as the SR measure is employed, or a more global assessment such as the SP measure, differences exist between centenarians and those in their 80 s, among centenarians in different living conditions, and across types of informants. Researchers examining the different resources that may contribute to extraordinary longevity and positive adaptation may find it essential to differentiate between age groups (oldest old and centenarians), residence status, and similar measures of interest, as well as account for differences based on reporter type.

\section{Acknowledgements}

The Georgia Centenarian Study (Leonard W. Poon, PI) is funded by 1PO1-AG17553 from the National Institute on Aging, a collaboration among The University of Georgia, Tulane University Health Sciences Center, Boston University, University of Kentucky, Emory University, Duke University, Wayne State University, Iowa State University, Temple University, and University of Michigan. Authors acknowledge the valuable recruitment and data acquisition effort from M. Burgess, K. Grier, E. Jackson, E. McCarthy, K. Shaw, L. Strong and S. Reynolds, data acquisition team manager; S. Anderson, E. Cassidy, M. Janke, and J. Savla, data management; M. Poon for project fiscal management.

\section{References}

$\checkmark 1$ Vaupel JW: The biodemography of aging. Popul Dev Rev 2004;30:48-62.

2 Harman D: Aging: overview. Ann NY Acad Sci 2001;928:1-21.

3 Ball MM, Perkins MM, Whittington FJ, et al: Managing decline in assisted living: the key to aging in place. J Gerontol B Psychol Sci Soc Sci 2004;59:S202-S212.

4 Mitchell JM, Kemp BJ: Quality of life in assisted living homes: a multidimensional analysis. J Gerontol B Psychol Sci Soc Sci 2000;55:P117-P127.

5 Street D, Burge S, Quadagno J, et al: The salience of social relationships for resident well-being in assisted living. J Gerontol B Psychol Sci Soc Sci 2007;62:S129-S134.
6 Martin P, Poon LW, Kim E, et al: Social and psychological resources in the oldest old. Exp Aging Res 1996;22:121-139.

7 Braungart Fauth E, Zarit SH, Malmberg B, Johansson B: Physical, cognitive, and psychosocial variables from the Disablement Process Model predict patterns of independence and the transition into disability for the oldest-old. Gerontologist 2007;47:613624.

$>8$ Burholt V, Windle G, Ferring D, et al: Reliability and validity of the Older Americans Resources and Services (OARS) Social Resources Scale in six European countries. J Gerontol B Psychol Sci Soc Sci 2007;62:S371S379.
9 Mavandadi S, Rook KS, Newsom JT: Positive and negative social exchanges and disability in later life: an investigation of trajectories of change. J Gerontol B Psychol Sci Soc Sci 2007;62:S361-S370.

10 Fillenbaum GG: Multidimensional Functional Assessment of Older Adults: The Duke Older Americans Resources and Services Procedures. Hillsdale, Lawrence Erlbaum Associates, 1994.

11 Cutrona C, Russell D: The provisions of social relationships and adaptation to stress; in Jones JH, Perlman D (eds): Advances in Personal Relationships. Greenwich, JAI Press, 1987, pp 37-67. 
12 Baltes P: On the incomplete architecture of human ontogeny: selection, optimization, and compensation as foundation of developmental theory. Am Psychol 1997;52:366380 .

13 Martin P, Martin M: Proximal and distal in fluences on development: the model of developmental adaptation. Dev Rev 2002;22:7896.

14 Gaugler JE, Duval S, Anderson KA, Kane RL: Predicting nursing home admission in the U.S.: a meta-analysis. BMC Geriatr 2007; $7: 13$.
15 Miller EA, Weissert WG: Predicting elderly people's risk for nursing home placement, hospitalization, functional impairment, and mortality: a synthesis. Med Care Res Rev 2000;57:259-297.

16 Martin P: Individual and social resources predicting well-being and functioning in the later years: conceptual models, research, and practice. Aging Int 2002;27:3-29.

17 Poon LW, Jazwinkski SM, Green RC, et al: Contributors of longevity and adaptation: findings and new directions from the Georgia Centenarian Study; in: Perls TT (ed): Exceptional Longevity. Baltimore, Johns Hopkins, 2007.

18 Folstein MF, Folstein SE, McHugh PR: 'Minimental state'. A practical method for grading the cognitive state of patients for the clinician. J Psychiatr Res 1975;12:189-198.
19 Herbert TB, Cohen S: Measurement issues in research on psychosocial stress; in: Kaplan HB (ed) Psychosical Stress: Perspectives on Structure, Theory, Life-Course, and Methods. San Diego, Academic Press, 1996, pp 295-332.

20 Reuben DB, Valle LA, Hays RD, et al: Measuring physical function in communitydwelling older persons: a comparison of selfadministered, interviewer-administered, and performance-based measures. J Am Geriatr Soc 1995;43:17-23. 